\title{
Physician perspectives on education, training, and implementation of complementary and alternative medicine
}

This article was published in the following Dove Press journal:

Advances in Medical Education and Practice

25 July 2017

Number of times this article has been viewed

\author{
Sejal J Patel' \\ Kathi J Kemper ${ }^{2}$ \\ Joseph P Kitzmiller ${ }^{3}$ \\ 'College of Public Health, The \\ Ohio State University, ${ }^{2}$ Center for \\ Integrative Health and Wellness, The \\ Ohio State Wexner University Medical \\ Center, ${ }^{3}$ Department of Biological \\ Chemistry and Pharmacology, \\ College of Medicine, The Ohio State \\ University, Columbus, $\mathrm{OH}$, USA
}

Correspondence: Joseph P Kitzmiller Department of Biological Chemistry and Pharmacology, College of Medicine, The Ohio State University, 5086 Graves Hall, 333 West Tenth Avenue, Columbus, $\mathrm{OH}$ 43210, USA

Tel +l 6142928438

Email joseph.kitzmiller@osumc.edu
Abstract: Over recent decades, the demand for complementary and alternative medicine (CAM) has continued to rise in the US. Like the practice of traditional Western medicine, CAM is associated with not only significant health benefits but also significant risks. Unlike traditional Western medicine, however, much of CAM use is less regulated and often occurs unbeknownst to a patient's medical doctor. The use of herbals, dietary supplements, and overthe-counter (OTC) medications can result in adverse effects, and many significant interactions can occur when their use is combined with allopathic medications. Even the more peripheral CAM practices (eg, acupuncture, massage, yoga, and Reiki) have associated risk (eg, adverse effects or worsening of physical injury and conditions). There is, however, impetus for change: both patients and physicians favor increasing physician knowledge of CAM and the synergistic implementation of CAM into routine clinical practice. Although improvement has been achieved from contemporary physician educational efforts, recently published results from patient and physician surveys strongly indicate that additional effort to increase physician knowledge of CAM is needed. Utilizing a 37-item survey and convenience-sampling methodology, we collected detailed information from 114 physicians, fellows, and residents from the Ohio State University Medical Center regarding impediments to increasing physician knowledge of CAM and its implementation in routine clinical practice. The aggregate results of our survey data showed that most physicians 1) desired to increase their knowledge of CAM, 2) believed that less than half of their patients were spontaneously reporting their use of CAM therapies, 3 ) were not aware of available evidence-based resources on CAM, 4) preferred case-based lectures for learning about $\mathrm{CAM}$, and 5) reported insufficient time during patient encounters as the primary barrier for increasing the implementation of CAM in routine clinical practice.

Keywords: attitudes, integrative medicine, survey, holistic medicine, clinical practice

\section{Introduction}

Nearly half of the adult patients in the US use complementary and alternative medicine (CAM) therapies to treat medical conditions or to improve their overall well-being, and current trends suggest that interest is growing. ${ }^{1-4}$ Despite this, $\sim 80 \%$ do not discuss their CAM use with their physician. ${ }^{5-7}$ Lack of physician-patient communication regarding CAM can be tremendously problematic, resulting in forgone opportunities to discuss potential interactions between pharmaceuticals and CAM therapies, misattribution of therapeutic benefits or side effects, and a reduced capacity of physicians to function in a truly integrative capacity. ${ }^{5,7-9}$ Patient perception that physicians lack interest in CAM has commonly been cited as a reason for patients' nondisclosure, and limited education and training regarding CAM likely contributes to limited physician-patient 
dialogue regarding CAM. ${ }^{1,6,10-13}$ Although leaders of the medical community have called on physicians to routinely include dialogue about CAM in their patient encounters (eg, reconciliation of all medications, including dietary supplements such as vitamins, minerals, and herbal products, is required at each patient encounter per the Joint Commission for the Accreditation for Hospitals [JCAHO]) and a growing number of academic medical centers in the US have renewed efforts to bolster training and education of CAM, evidence of their impact remains scant. ${ }^{1,9,13-16}$

At The Ohio State University Medical Center (OSUMC), traditional (lectures, workshops, and conferences) and contemporary (online databases and interactive websites) modes of education have been developed to educate physicians, medical staff, and trainees about CAM. ${ }^{9}$ An undergraduate Minor in Integrative Health program was established in OSU's College of Medicine in 2006; a Medical Student Interest Group in Integrative Medicine was launched in 2012; an elective in Integrative Medicine for residents of Family Medicine and a special collection of integrative medicine resources in the University's Health Sciences Library were made available starting in 2013; and online training in mind-body skills, as well as herbs and dietary supplements, has been available since 2014. ${ }^{9}$ Most of the CAM education and training initiatives, however, have been provided on an elective basis, and the subsequent benefits remain unknown. The physician survey we developed for this short report was designed to collect detailed information from physicians regarding their perspectives on education, training, and implementation of CAM. Resulting observations may play a vital role in informing curriculum development and evaluation efforts at our medical center and elsewhere.

\section{Methods}

For this study, we developed an online anonymous survey designed to collect detailed information from attending, fellow, and resident physicians at the OSUMC regarding their attitudes on CAM, their patient-physician dialogue regarding CAM, and their perceived impediments to increasing their knowledge of CAM and implementing it in their routine clinical practice. The 37-item survey and the recruitment and analysis protocols were approved by the institutional review board (IRB) at the Ohio State University (OSU). For purposes of the survey, CAM was defined similar to the definition used by the National Health Interview Survey: dietary supplements (vitamins, minerals, probiotics, herbs, and combinations of these products), acupuncture, massage, homeopathy, meditation, hypnosis, biofeedback, yoga, or systems, such as Tradi- tional Chinese Medicine, shamanism, and Ayurvedic medicine (not including prayer, physical therapy, or therapies provided by psychologists, dietitians, and social workers). ${ }^{5}$

Recruitment of a convenience sample was achieved during May 2015 and February 2016 via broadly distributed flyer and leaflet advertisements, and email invitations were routinely sent to OSUMC physicians, fellows, and residents. Participants provided informed consent to participate by clicking on a link ("Take Me to the Survey") embedded in the survey invitation email. As approved by the OSU IRB, the link was clearly labeled to indicate that informed consent to participate was acknowledged by clicking the link. Survey participants were provided a US\$20 Amazon gift card to compensate them for their time (estimated to be 10-15 minutes). Secondary to the limited financial support for this project, the survey was concluded after 114 physicians participated. Their survey responses were collected and deidentified using Research Electronic Data Capture (REDCap), a secure webbased application for building and managing online surveys and databases. ${ }^{17}$ The counts and percentages for each survey item were determined and tabulated.

\section{Results}

Examination of the aggregate demographic data (Table 1) showed that most physician participants were $<50$ years of age, most were Caucasian, most practiced medicine as a specialist (eg, emergency medicine, cardiology, dermatology, internal medicine, neurology, pulmonary and critical care medicine, psychiatry, and surgical specialties), and about half were male.

Examination of the aggregate survey responses regarding physician-patient dialogue and patient use of CAM (Table 2) found disparity between the perceived frequency of CAM use and the perceived frequency of patients' reporting of their CAM use. The highest percentage (42\%) of physicians believed that $20 \%-40 \%$ of their patients use some form of CAM therapy, while the highest percentage $(67 \%)$ of physicians believed that $<20 \%$ of their patients spontaneously reported their CAM use without prompting or direct questioning. Furthermore, disparity between the perceived importance and the reported occurrence of physicians querying about CAM use was also found. Although the majority of physicians acknowledged (56\% agreed and $31 \%$ strongly agreed) that physicians should routinely ask their patients about CAM use, the highest percentage of physicians (42\%) responded that they directly ask patients about their use of CAM in only $0 \%-20 \%$ of their routine visits.

Several observations were made from the aggregate analyses of survey responses regarding CAM training, learning 
resources, and perceived barriers (Table 3). Accordingly, 25\% reported that "CAM was required" and $35 \%$ reported "elective learning about CAM" during medical school, and only $15 \%$ reported having learned about CAM during residency training. Fewer than half were familiar with evidence-based resources on CAM in the medical journals they routinely consulted, on the Internet, or in the textbook resources available at our medical center's health sciences library. In addition to lack of training and limited awareness of CAM resources, physicians reported several additional barriers

Table I Demographics of physician survey participants

\begin{tabular}{ll}
\hline Characteristics & $\mathbf{n}(\%)$ \\
\hline Age, years & \\
$<30$ & $46(40)$ \\
$30-40$ & $47(4 \mathrm{I})$ \\
$40-50$ & $13(1 \mathrm{I})$ \\
$>50$ & $8(7)$ \\
Gender & \\
Male & $53(47)$ \\
Female & $61(53)$ \\
Ethnicity & \\
Hispanic or Latino & $1(1)$ \\
Non-Hispanic or non-Latino & $113(99)$ \\
Race & \\
Asian & $21(19)$ \\
Black or African American & $4(3)$ \\
Native Hawaiian or other Pacific Islander & $1(1)$ \\
Caucasian & $87(77)$ \\
Percentage of clinical time involving primary care & \\
$<25$ & $24(21)$ \\
$25-49$ & $53(47)$ \\
$50-74$ & $14(12)$ \\
$>75$ & $23(20)$ \\
Primary area of practice & \\
Primary care & $22(19)$ \\
Specialty care & $92(81)$ \\
\hline
\end{tabular}

to talking with their patients about CAM. More than $80 \%$ perceived that insufficient time was a barrier, and only $8 \%$ reported that lack of third party reimbursement was problematic. Other perceived barriers included lack of availability of physicians and nonphysicians for CAM consultation. Furthermore, 33\% disagreed that other physicians at their institution were available to consult regarding CAM, and 24\% disagreed that other health care providers (nonphysicians) at their institution were readily available to consult regarding CAM. Only $22 \%$ physicians reported that senior faculty and administrative leaders encouraged CAM physician-patient dialogue, and significant numbers had positive preferences for case-based lectures (58\%), experiential workshops (55\%), and case-based interactive online curricula or webinars $(48 \%)$ for increasing their knowledge of CAM.

\section{Discussion}

Although most physicians (87\%) acknowledged that CAM use is common among their patients and that querying patients about CAM is important, many (42\%) reported that they inquire about CAM use at $<20 \%$ of their patient encounters. This highlights the need for strategies aimed at increasing and improving patient-physician dialogue and reconciliation of CAM therapies.

Physician perspectives reflecting a need for increased knowledge of CAM have been reported, ${ }^{1}$ and the majority of physicians in this study favored increasing their knowledge of CAM. We also observed a stark disconnect regarding physician's familiarity with the evidenced-based CAM resources readily available to them. Some degree of unfamiliarity was expected, but the severity of the disconnect uncovered in our analysis was substantial. This highlights another significant impetus for change and another opportunity for interventions

Table 2 Survey items regarding physician-patient dialogue and patient use of CAM

\begin{tabular}{|c|c|c|c|c|c|c|}
\hline Survey items & $\begin{array}{l}0-20 \% \text { of } \\
\text { Patients }\end{array}$ & $\begin{array}{l}2 \mathrm{I}-40 \% \text { of } \\
\text { Patients }\end{array}$ & $\begin{array}{l}41-60 \% \text { of } \\
\text { Patients }\end{array}$ & $\begin{array}{l}61-80, \% \text { of } \\
\text { Patients }\end{array}$ & $\begin{array}{l}8 \mathrm{I}-100 \% \text { of } \\
\text { Patients }\end{array}$ & Missing, n \\
\hline $\begin{array}{l}\text { What percentage of your patients do you think } \\
\text { use some form of CAM therapies? }\end{array}$ & $31(27)$ & $47(42)$ & $23(20)$ & $11(10)$ & $I(I)$ & I \\
\hline $\begin{array}{l}\text { What percentage of your patients spontaneously } \\
\text { reports their CAM use without prompting or } \\
\text { direct questioning? }\end{array}$ & $77(68)$ & $23(20)$ & $10(9)$ & $3(3)$ & $0(0)$ & I \\
\hline $\begin{array}{l}\text { In what percentage of your routine patient } \\
\text { encounters do you directly ask your patient about } \\
\text { their use of CAM? }\end{array}$ & $47(42)$ & $18(16)$ & $26(23)$ & $15(13)$ & $7(6)$ & I \\
\hline Perspective & $\begin{array}{l}\text { Strongly } \\
\text { agree }\end{array}$ & Agree & Neutral & Disagree & $\begin{array}{l}\text { Strongly } \\
\text { disagree }\end{array}$ & Missing, n \\
\hline $\begin{array}{l}\text { Physicians should inquire about CAM use, even when } \\
\text { patients do not spontaneously disclose CAM use }\end{array}$ & $34(3 I)$ & $62(56)$ & $12(11)$ & $2(2)$ & $0(0)$ & I \\
\hline
\end{tabular}

Note: Values presented as $\mathrm{n}(\%)$.

Abbreviation: CAM, complementary and alternative medicine. 
Table 3 Survey items regarding CAM training, learning resources, and perceived barriers

\begin{tabular}{|c|c|c|c|c|c|c|}
\hline Statements & $\begin{array}{l}\text { Strongly } \\
\text { agree } \\
(\%)\end{array}$ & $\begin{array}{l}\text { Agree } \\
(\%)\end{array}$ & $\begin{array}{l}\text { Neutral } \\
(\%)\end{array}$ & $\begin{array}{l}\text { Disagree } \\
(\%)\end{array}$ & $\begin{array}{l}\text { Strongly } \\
\text { disagree } \\
(\%)\end{array}$ & Missing, $\mathbf{n}$ \\
\hline \multicolumn{7}{|l|}{ Statements regarding CAM training } \\
\hline $\begin{array}{l}\text { Training in CAM was a required component of my medical school } \\
\text { curriculum }\end{array}$ & $3(3)$ & $25(22)$ & $23(21)$ & $44(39)$ & $17(15)$ & 2 \\
\hline $\begin{array}{l}\text { Training in CAM was an elective component of my medical school } \\
\text { curriculum }\end{array}$ & $8(7)$ & $31(28)$ & $19(17)$ & $37(33)$ & $17(15)$ & 2 \\
\hline $\begin{array}{l}\text { Training in CAM was a component of my medical residency program } \\
\text { Statement regarding CAM knowledge and CAM learning resources }\end{array}$ & $4(4)$ & $12(11)$ & $27(25)$ & $52(49)$ & $12(11)$ & \\
\hline $\begin{array}{l}\text { I need to gain additional knowledge to properly counsel patients } \\
\text { on CAM }\end{array}$ & $37(32)$ & $64(56)$ & II (10) & $I(I)$ & $I(I)$ & 0 \\
\hline Evidence-based resources regarding CAM are readily available to me & $7(6)$ & $28(34)$ & $32(28)$ & $32(28)$ & $4(4)$ & I \\
\hline $\begin{array}{l}\text { Government-sponsored websites (eg, US FDA) regarding CAM are } \\
\text { readily available to me }\end{array}$ & II (I0) & $35(31)$ & $30(27)$ & $31(27)$ & $6(5)$ & 1 \\
\hline $\begin{array}{l}\text { University Health Sciences Library websites regarding CAM are readily } \\
\text { available to me }\end{array}$ & $8(7)$ & $39(35)$ & $21(19)$ & $36(33)$ & $7(6)$ & 3 \\
\hline $\begin{array}{l}\text { Medical textbooks regarding CAM are readily available to me at the } \\
\text { University Health Library }\end{array}$ & $6(5)$ & $39(34)$ & $27(24)$ & $40(35)$ & $2(2)$ & 0 \\
\hline $\begin{array}{l}\text { Evidence-based information regarding CAM is readily available to me in } \\
\text { journals I routinely consult }\end{array}$ & $2(2)$ & $23(20)$ & $32(28)$ & $49(43)$ & $8(7)$ & 0 \\
\hline \multicolumn{7}{|l|}{ Statements regarding barriers to CAM learning and implementation } \\
\hline $\begin{array}{l}\text { One of the barriers limiting my ability to talk with patients about CAM } \\
\text { during office visits is insufficient time }\end{array}$ & $336(33)$ & $53(48)$ & $15(14)$ & $6(5)$ & $0(0)$ & 4 \\
\hline $\begin{array}{l}\text { One of the barriers limiting my ability to talk with patients about CAM } \\
\text { during hospitalizations or emergency room visits is insufficient time }\end{array}$ & $37(33)$ & $53(48)$ & $14(13)$ & $6(5)$ & $0(0)$ & 4 \\
\hline $\begin{array}{l}\text { Senior faculty and leaders at my institution encourage physicians to } \\
\text { discuss CAM with their patients }\end{array}$ & $3(3)$ & $21(19)$ & $45(4 I)$ & $33(30)$ & $8(7)$ & 4 \\
\hline $\begin{array}{l}\text { There is adequate financial reimbursement by third party payers for } \\
\text { time spent talking with patients about CAM }\end{array}$ & $0(0)$ & $9(8)$ & $42(38)$ & $38(35)$ & $21(19)$ & 4 \\
\hline $\begin{array}{l}\text { At my institution, other physicians are readily available to consult } \\
\text { regarding CAM }\end{array}$ & $7(6)$ & $36(33)$ & $31(28)$ & $30(27)$ & $6(6)$ & 4 \\
\hline $\begin{array}{l}\text { At my institution, other health care providers (nonphysicians) are } \\
\text { readily available to consult regarding CAM }\end{array}$ & $8(7)$ & $44(40)$ & $32(29)$ & $22(20)$ & $4(4)$ & 4 \\
\hline
\end{tabular}

Note: Values presented as $\mathrm{n}(\%)$.

Abbreviations: CAM, complementary and alternative medicine; FDA, US Food and Drug Administration.

focused on increasing awareness of CAM and increasing the awareness and utilization of CAM knowledge and learning resources. As Internet-based resources and case-based interactive learning were preferred by the physicians in this study, they should be strongly emphasized in future CAM education and training efforts.

The relatively low number of participants in this study was a limitation. As the awarded budget allowed for only 114 participants, the use of convenience sampling methodology was necessitated. As the conditions of random sampling were not feasible, bias may have been introduced in that physicians who chose to participate may have had different experiences, interests, or attitudes regarding CAM compared to those who chose not to seek participation. Furthermore, our findings may be limited in that thousands of physicians are employed at the OSUMC and we surveyed only 114 . Although convenience sampling has significant limitations (eg, biases and lower generalizability), the survey data collected in this study provide important insights that can inform future studies as well as CAM education and training efforts. Future studies should aim to utilize random sampling and include a larger sample size. Participants' current level of practice (resident, fellow, or attending) was not acquired in our survey. This represents an important limitation of our report as survey responses may likely have been related to the participant's temporal proximity to medical school or postgraduate training.

As increased efforts focused on the inclusion of CAM education and training in medical school, residency, and physician continuing medical education programs are warranted, support from institutions (eg, academic medical centers and hospitals), governing bodies (eg, US Food and Drug Administration [FDA]), and leading professional organizations (eg, American Medical Association) is also paramount. Along with examining whether the role (resident, fellow, or attending) or number of years out of training has 
any influence, designs of future studies should examine also whether physicians' specialty or whether their practice as part of an interdisciplinary team has influence on their perspectives of CAM.

\section{Conclusion}

Patient demand for the inclusion of medicine and integrative medicine approaches to health care that are more precise is increasing in the US and other developed countries, resulting in increased need for CAM education, training, and resources for physicians and other health care providers. Physicians acknowledge the importance of acquiring knowledge and training of CAM, and this short report provides meaningful insight regarding physician perspectives on education, training, and implementation of CAM.

\section{Acknowledgments}

The authors thank the physicians who participated in this survey. They also thank The Center for Integrative Health and Wellness at The Ohio State University Medical Center for providing a research award to fund implementation of the physician survey.

\section{Disclosure}

The authors report no conflicts of interest in this work.

\section{References}

1. Maha N, Shaw A. Academic doctors' views of complementary and alternative medicine (CAM) and its role within the NHS: an exploratory qualitative study. BMC Complement Altern Med. 2007;7:17.

2. Clarke TC, Black LI, Stussman BJ, Barnes PM, Nahin RL. Trends in the use of complementary health approaches among adults: United States, 2002-2012. Natl Health Stat Report. 2015;(79):1-16.

3. Nahin RL, Barnes PM, Stussman BJ, Bloom B. Costs of complementary and alternative medicine (CAM) and frequency of visits to CAM practitioners: United States, 2007. Natl Health Stat Report. 2009;(18): $1-14$.
4. Kemper KJ, Vohra S, Walls R; Task Force on Complementary and Alternative Medicine; Provisional Section on Complementary, Holistic, and Integrative Medicine. American Academy of Pediatrics. The use of complementary and alternative medicine in pediatrics. Pediatrics. 2008;122(6): 1374-1386.

5. Chao MT, Wade C, Kronenberg F. Disclosure of complementary and alternative medicine to conventional medical providers: variation by race/ ethnicity and type of CAM. JNatl Med Assoc. 2008;100(11):1341-1349.

6. Davis EL, Oh B, Butow PN, Mullan BA, Clarke S. Cancer patient disclosure and patient-doctor communication of complementary and alternative medicine use: a systematic review. Oncologist. 2012;17(11): 1475-1481.

7. Robinson A, McGrail MR. Disclosure of CAM use to medical practitioners: a review of qualitative and quantitative studies. Complement Ther Med. 2004;12(2-3):90-98.

8. McCune JS, Hatfield AJ, Blackburn AA, Leith PO, Livingston RB, Ellis GK. Potential of chemotherapy-herb interactions in adult cancer patients. Support Care Cancer. 2004;12(6):454-462.

9. The Ohio State University Medical Center [webpage on the Internet]. Integrative Medicine Education. Available from: https://wexnermedical.osu.edu/integrative-complementary-medicine/education. Accessed April 1, 2017.

10. Sidora-Arcoleo K, Yoos HL, Kitzman H, McMullen A, Anson E. Don't ask, don't tell: parental nondisclosure of complementary and alternative medicine and over-the-counter medication use in children's asthma management. J Pediatr Health Care. 2008;22(4):221-229.

11. Tasaki K, Maskarinec G, Shumay DM, Tatsumura Y, Kakai H. Communication between physicians and cancer patients about complementary and alternative medicine: exploring patients' perspectives. Psychooncology. 2002;11(3):212-220.

12. Owen D, Lewith GT. Teaching integrated care: CAM familiarization courses. Med J Aust. 2004;181(5):276-278.

13. The Joint Commission [homepage on the Internet]. Using medication reconciliation to prevent errors. Available from: http://www.ihi.org/ resources/Pages/Publications/UsingmedicationreconciliationtopreventerrorsJCAHOSentinelEventAlert35.aspx. Accessed July 4, 2017.

14. Karpa K. Development and implementation of an herbal and natural product elective in undergraduate medical education. BMC Complement Altern Med. 2012;12:57.

15. Stewart MA. Effective physician-patient communication and health outcomes: a review. CMAJ. 1995;152(9):1423-1423.

16. Street RL, Makoul G, Arora NK, Epstein RM. How does communication heal? Pathways linking clinician-patient communication to health outcomes. Patient Educ Couns. 2009;74(3):295-301.

17. Harris PA, Taylor R, Thielke R, Payne J, Gonzalez N, Conde JG. Research electronic data capture (REDCap) - a metadata-driven methodology and workflow process for providing translational research informatics support. J Biomed Inform. 2009;42(2):377-381.
Advances in Medical Education and Practice

\section{Publish your work in this journal}

Advances in Medical Education and Practice is an international, peerreviewed, open access journal that aims to present and publish research on Medical Education covering medical, dental, nursing and allied health care professional education. The journal covers undergraduate education, postgraduate training and continuing medical education

\section{Dovepress}

including emerging trends and innovative models linking education, research, and health care services. The manuscript management system is completely online and includes a very quick and fair peer-review system. Visit http://www.dovepress.com/testimonials.php to read real quotes from published authors. 